\title{
Social representations of HIVIAIDS in five Central European and Eastern European countries: a multidimensional analysis
}

\author{
Robin Goodwin, ${ }^{1}$ Anna Kwiatkowska, ${ }^{2}$ Anu Realo, ${ }^{3}$ \\ Alexandra Kozlova, ${ }^{4}$ Lan Anh Nguyen $\mathrm{LuU}^{5} \&$ \\ GeOrge NizharadzE ${ }^{6}$ \\ ${ }^{1}$ Brunel University, UK, ${ }^{2}$ Warsaw School of Advanced Social Psychology, Poland, ${ }^{3}$ University of \\ Tartu, Estonia, ${ }^{4}$ St. Petersburg University, Russia, ${ }^{5}$ Eotvos Lorand University, Hungary $\mathbb{}$ \\ ${ }^{6}$ Academy of Sciences, Georgia
}

\begin{abstract}
Cognitive processing models of risky sexual behaviour have proliferated in the two decades since the first reporting of HIVIAIDS, but far less attention has been paid to individual and group representations of the epidemic and the relationship between these representations and reported sexual behaviours. In this study, 494 business people and medics from Estonia, Georgia, Hungary, Poland and Russia sorted free associations around HIVIAIDS in a matrix completion task. Exploratory factor and multidimensional scaling analyses revealed two main dimensions (labelled 'Sex' and 'Deadly disease'), with significant cultural and gender variations along both dimension scores. Possible explanations for these results are discussed in the light of growing concerns over the spread of the epidemic in this region.
\end{abstract}

\section{Introduction}

Although a relatively recent epidemic in Central and Eastern Europe, HIV infection in this region is now increasing at a faster rate than anywhere else in the world (UNAIDS, 2002b). In most of these countries transmission has been primarily through injecting and the sharing of needles and syringes (Donoghoe, 2003; Hamers \& Downs, 2003), with an estimated 1\% of the population of Eastern Europe and Central Asia injecting illicit drugs (UNAIDS, 2002b), although the growth of sex work and casual sexual encounters (Borisenko et al., 1999; Kalichman, 1998), the deterioration of the health care system (Atlanti et al., 2000) and the increasing mixing of populations due to civil unrest in some regions (Borisenko et al., 1999; Parker et al., 2000; Rhodes et al., 1999) have contributed towards differential rates of infection and different forms of transmission across different nations. As a result, in some countries (such as Hungary, where infection rates have largely stabilized) HIV transmission has been primarily through homosexual contacts between men (UNAIDS, 2002b), whilst in

Address for correspondence: Robin Goodwin, Department of Human Sciences, Brunel University, Uxbridge UB8 3PH, UK. Tel: +44 (01895) 816200; Fax: +44 (01895) 203207; E-mail: Robin.Goodwin@brunel.ac.uk 
multicultural Estonia illicit drug use and subsequent HIV infection have been largely limited to the Russian-speaking minority (Estonian Drug Monitoring Centre, 2003). As yet, however, there has been little empirical research into the social and cultural forces that might underlie cultural differences in transmission routes and subsequent infection.

Most of the existing psychological research into HIV/AIDS has focused on cognitive explanations which link individual knowledge, attitudes and beliefs to sexual practices (Abrahams et al., 1998; Campbell, 2001; Sheeran et al., 1999). Although this work has been valuable in providing important insights into the individual-level factors underlying safer sexual behaviours (Albarracín et al., 2001; Sheeran et al., 1999), even those working from within this cognitive paradigm have called for a wider understanding of the social relations and social environment in which sexual activity takes place (Fife-Schaw, 1997; Sheeran et al., 1999). What is needed is an understanding of the 'lay', 'common sense' perspectives taken by different individuals when they try to understand this complex epidemic - and the relationship between these perspectives and an individual's risk-taking behaviour (Campbell, 2001). Such a study can be a vital aid to understanding the normative factors that influence socially complex behaviours, such as the carrying and use of condoms, and can help illuminate the situational barriers that might prevent an intention from turning into actual action (FifeSchaw, 1997; Sheeran et al., 1999). In doing so, it can also illustrate how the HIV/AIDS epidemic can be viewed as part of wider concerns over the costs of 'Western' sexual practices in post-Communist Europe (Headley, 1998; Rivkin-Fish, 1999), concerns which are themselves part of a broader debate on liberalization and social modernization across Europe (Rosenbrock et al., 2000).

\section{The theory of social representations}

One important theoretical approach to understanding 'lay perspectives' on sexual disease can be found in the theory of social representations (Moscovici, 1984). Social representations can be seen as a collection of different folk theories, 'common sense' and everyday knowledge that serve important social functions in guiding and justifying actions, maintaining social identity and allowing for communication between group members (Páez et al., 1991; Wagner, 1995). Individuals faced with a complex and frightening new scientific concept (such as HIV/AIDS) will seek to integrate this new concept into their everyday cognitions, lifestyles and behaviours (Farr, 1984). Thus, for example, in Breakwell's (1993, p. 195) work on riskiness and sexual activity, HIV risk-taking was positively correlated with individual representations of HIV that diminish the risks attached. In her study, sexual risk-takers were more likely to believe that HIV could be cured, and that someone with HIV/AIDS could be identified simply by sight. At the same time, social representations are negotiated and spread through interactions with group members (Bergmann, 1999; Moscovici \& Perez, 1997), with group members trying to fit their understanding of the disease within pre-existing prejudices and discriminations (Joffe, 1996; Kitzinger, 1995). This can lead to a 'moral panic', where individuals or even whole societies seek to psychologically distance themselves from particular groups (Lear, 1995). As a consequence, governments may discriminate against those infected or 'outsiders' suspected of carrying the virus (e.g. through the introduction of compulsory HIV tests for foreigners entering the country), whilst particular groups may target 'out-groups' suspected of 'risky' or 'immoral' behaviours (see, for example, Joffe, 1996, on hostility towards homosexuals). 


\section{The present study}

The research reported here focuses on representations of HIV/AIDS and their relationship to sexual behaviour in five Central European and Eastern European countries: Estonia, Georgia, Hungary, Poland and Russia. These countries vary not only in the spread of the epidemic in each nation but also in political structure, influence and nature of the religion(s) practised and level of economic investment and growth - all factors previously identified as likely to have important implications for both the spread of infection and the extent to which particular representations may be accepted or even propagated (see, for example, Danziger (1994) on the role of religion in representations of out-groups and HIV/AIDS in Poland). Estonia and Georgia were both parts of the Former Soviet Union and until recently have reported generally low rates of HIV infection (less than 50 cases of AIDS had been reported in both countries at the beginning of our study, in 1998). ${ }^{1}$ In Hungary and Poland, rates of infection are relatively low and stable (UNAIDS, 2002b), with little evidence of a marked increase in AIDS incidence (Poland: 794 AIDS cases; Hungary: 328 AIDS cases at the start of this research). In contrast, the Russian Federation has seen a marked escalation in the HIV epidemic, associated primarily with injecting drug use and the sharing of needles and syringes. Here, new infections increased almost 20-fold between 1998 and mid-2002, with a conservative estimate of at least 700,000 adults and children living with HIV/AIDS at the end of 2001 (UNAIDS, 2002b).

Whilst the increase in HIV infection in this region has been largely associated with illicit drug use amongst young people (Hamers \& Downs, 2003), in the present study we were particularly interested in exploring the social representations of two, highly influential professional groups: business people and medical professionals. Business people were selected as an economically significant group whose mobility, lifestyle and attitudes may make them likely to engage in particular, higher risk activities, and here we focus on risk associated with the sexual practice of these professional people (Barnett et al., 2000). Social stereotypes influence health care professionals' commitment to treatment and prevention of infection (Echebarria \& Páez, 1989; Markova \& Wilkie, 1987; Morin et al., 1996) and health care professionals were chosen as a group whose representations of the epidemic were likely to be highly influential in these transient societies (Nascimento-Schulze et al., 1995; Rivkin-Fish, 1999). Both the groups studied in this study were raised and educated during the Soviet period, during which information about the sexual disease epidemic was couched in strong 'moral' overtones. Such an education is likely to have contributed to the low levels of knowledge about the virus and the low condom use regularly reported in this region (e.g. Amirkhanian et al., 2001; Dehne et al., 2000), significant vulnerability factors that may feed the emerging sexual transmission of the epidemic in this region (Hamers \& Downs, 2003).

Social representations research has typically operated on a number of levels of assessment and employed a diversity of methodologies (Bergmann, 1999; Breakwell \& Canter, 1993; Doise et al., 1993; Wagner, 1995). Given the lack of previous research into representations of HIV/AIDS in Central/Eastern Europe, the present study primarily uses exploratory statistical techniques to conduct two sets of analyses. First, the structure and content of representations of HIV/AIDS are explored using factor analysis techniques to analyze sample and country differences in free associations around the word 'AIDS'. Second, a multidimensional scaling analysis (MDS) is conducted, which allows for the verification of the principal dimensions of representation and for the analysis of the relationship between theoretically relevant stimulus objects and dimension scores. 


\section{Method}

\section{Participants}

Respondents were drawn from three professional groups: business people (51\%), nurses (20\%) and doctors (29\%). All respondents were aged between 25 and 57 (mean age 33.2, $\mathrm{SD}=7.1$ ). Table 1 gives a breakdown of participants by country and occupational group: 511 participants completed the first stage of the study, 494 the second stage, with $30 \%$ of the respondents participating in both stages of the data collection. All participants were taken from the majority population in each country (i.e. Russian nationals in Russia, Estonian nationals in Estonia, etc.).

Participants were chosen to be as representative as possible of these professional groups. Respondents were recruited primarily during advanced professional training courses at medical schools or during business training courses taught by the research team or their colleagues, with data collection taking place during 1998 and 1999. Eighty-six per cent of those contacted agreed to participate. Participants overall were generally well educated, with $62 \%$ having completed university, although only $38 \%$ of nurses had continued beyond the 'special secondary' level of education. Polish respondents were overwhelmingly Catholic (93\% of the sample) and a further 53\% of Hungarian respondents were also Catholic. The Orthodox Church was strongly represented in Georgia (96\% of respondents were Georgian Orthodox) and Russia (75\% of participants were Russian Orthodox), whereas $71 \%$ of Estonian respondents reported that they were 'not religious'.

\section{Procedure}

Data collection was in two stages: a free association task and a matrix task.

Stage 1: Free associations. Free association techniques are particularly valuable when assessing the most salient and relevant associations with a concept (Mannetti \& Tanucci, 1993). Our first group of respondents were instructed to write 'everything that comes into your mind when I say the word AIDS' (Doise et al., 1993; Mannetti \& Tanucci, 1993). Respondents were asked to write as many responses as possible and to be unrestricted in their associations. Two judges examined a full and translated list of these associations and worked independently to aggregate semantically similar words (Di Giacomo, 1980), identifying the most frequently listed words from across the sample to use for our analyses (Kappa for inter-rater agreement $=0.90$ ).

Stage 2: Matrix preparation. Eleven words were selected as the most frequently occurring terms across the sample (see Table 2). Each of these words, plus the term 'HIV/AIDS', was then

Table 1. Numbers of respondents by country and occupation

\begin{tabular}{lcccccc}
\hline & Estonia & Georgia & Hungary & Poland & Russia & Totals \\
\hline Stage 1 & & & & & & \\
$\quad$ Business & 54 & 52 & 50 & 50 & 50 & 256 \\
$\quad$ Health professionals & 50 & 52 & 50 & 50 & 53 & 255 \\
Stage 2 & & & & & & \\
$\quad$ Business & 48 & 51 & 50 & 51 & 51 & 251 \\
$\quad$ Health professionals & 43 & 51 & 50 & 49 & 50 & 243 \\
\hline
\end{tabular}


Table 2. Factor loadings of the stimulus words (principal component analysis, varimax rotation) and number of respondents making each association with the word 'AIDS'

\begin{tabular}{lccc}
\hline & $\begin{array}{c}\text { Factor 1 } \\
\text { 'Deadly disease' }\end{array}$ & $\begin{array}{c}\text { Factor } 2 \\
\text { 'Sex' }\end{array}$ & $\begin{array}{c}\text { Number of free } \\
\text { associations }\end{array}$ \\
\hline Disease & $\mathbf{0 . 8 0 2}$ & -0.014 & 270 \\
Death & $\mathbf{0 . 7 7 9}$ & -0.178 & 172 \\
Fear & $\mathbf{0 . 7 4 5}$ & -0.079 & 106 \\
Blood & $\mathbf{0 . 7 0 8}$ & 0.040 & 160 \\
Illicit drugs & $\mathbf{0 . 6 7 5}$ & 0.006 & 160 \\
AIDS & 0.572 & 0.243 & 41 \\
Casual sex & 0.007 & $\mathbf{0 . 8 2 3}$ & 120 \\
Condoms & -0.131 & $\mathbf{0 . 7 9 8}$ & 66 \\
Prostitute & 0.007 & $\mathbf{0 . 7 7 0}$ & 117 \\
Sex & -0.234 & $\mathbf{0 . 7 6 5}$ & 148 \\
Homosexuality & 0.227 & $\mathbf{0 . 5 1 6}$ & 66 \\
Africa & 0.229 & -0.157 & \\
\hline
\end{tabular}

Note. Loadings above 0.30 are shown in bold type.

written on a separate card. For the matrix task, each respondent was presented with one card (here termed the 'standard' e.g. blood) and asked to select the word from the remaining 11 most similar to this standard (e.g. prostitute). Once this word was removed, the respondent was asked to select the next word most similar to the standard and this was repeated until all 11 compared words were ordered according to their similarity with the standard. These similarities were then entered onto a 12 (row) $\times 12$ (column) matrix, one for each respondent, and then entered into the complete data set. In each $12 \times 12$ matrix, the standard words were given in rows and the remaining 11 words in columns. For instance, the first row in each matrix reflected a respondent's order of the 11 words (from 0 to 11 ) according to their similarity with the first standard word (AIDS), the second row in the matrix reflected a respondent's order of the 11 words according to their similarity with the second standard word (Africa) and so on.

\section{Results}

Free associations

Our 511 respondents produced a total of 1,480 responses. Table 2 includes a list of the 11 most frequently occurring words, with the number of participants who made each association. As can be seen from the table, participants were most likely to associate AIDS with 'Disease', 'Death', 'Blood' and 'Illicit drugs'.

\section{Factor analysis}

The first analysis focused on the overall structure of our data. The data matrix of 12 (rows) by 6,036 (cases) was transformed for each respondent so that rows were turned into columns and vice versa. As a result, in every new 12 (row) $\times 12$ (column) matrix, the standard words were given in columns and the remaining 11 words in rows. A principal component analysis followed by varimax rotation was performed on this data set. A scree-test suggested a twofactor solution that explained $51.2 \%$ of the total variance. The two-factor solution was nearly 


\section{R. GOODWIN ET AL.}

simple: all words (except Africa) had significant loadings (above 0.30) on only one factor. The words and factor loadings are shown in Table 2.

The first factor was termed 'Deadly disease' and the second 'Sex'. AIDS, Blood, Death, Disease, Illicit drugs and Fear all had high loadings on this first factor. Casual sex, Condom, Homosexuality, Prostitute and Sex had their primary loadings on the second factor. Figure 1 represents these factor positions pictorially. As can be seen, Africa stands clearly apart from the other words and thereby does not appear to be meaningfully related to either AIDS or any other term used in this study. AIDS, however, appears to be more closely related to concepts such as Blood, Illicit drugs, Disease, Fear and Death and, more remotely, to Homosexuality.

Next, the analysis considered whether or not the same structure of 12 stimulus words would apply to all five countries involved in the study. For that purpose, a principal component analysis was performed separately for each country. Generally speaking, in all five samples the same two factors - 'Deadly disease' and 'Sex'-emerged. However, there were some notable differences in factor loadings across the five countries. The word AIDS, for instance, had low secondary loadings on the second factor ('Sex') in the Estonian (0.33) and Georgian (0.31) samples; whereas Africa loaded relatively highly on Factor 1 ('Deadly disease') in the Hungarian (0.32), Polish (0.36) and Russian (0.40) samples. In the Georgian sample, the word Homosexuality had equally moderate loadings on both factors $(0.40$ and 0.38 , respectively).

To examine how well the factor structure in five samples matches the shared, general factor structure (see Figure 1), a series of Procrustes rotations were performed. In such leastsquared targeted rotation, the data to be examined are rotated to maximum fit with a hypothesized or established target matrix (see Kallasmaa et al., 2000). In these analyses, the varimax two-factor structures of each country were rotated to maximum similarity with the shared factor matrix ('target') shown in Table 2. Next, factor and variable congruence coefficients were calculated between the target matrix and the five Procrustes-rotated replication matrices. In general, the factor and item congruences were reasonably high in all five samples. The factor congruence coefficients ranged from 0.98 (Russia) to 1.00

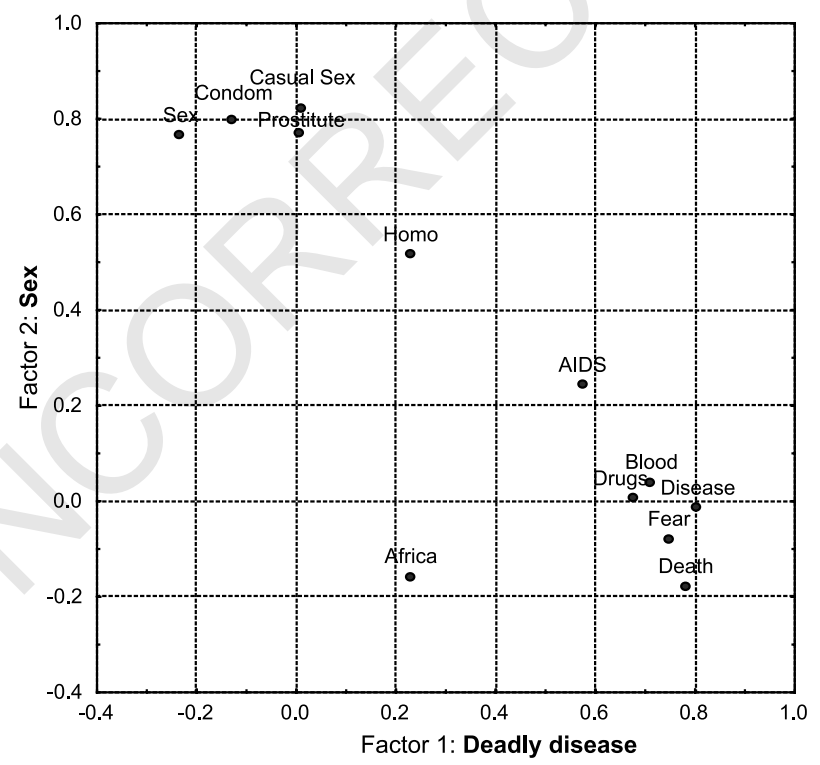

FIG. 1. Plot of the factor loadings for the whole sample (PCA, varimax normalized, two-factor solution). 
(Estonia) and all item congruence coefficients (except three) were above 0.98. There was just one main exception in the Russian sample, where the item congruence coefficient for Africa was 0.71. Here, Africa grouped closely with AIDS and other words from the second factor ('Deadly disease').

\section{Multidimensional scaling analysis}

The factor analysis was complemented with a multidimensional scaling analysis using the INDSCAL package (Individual Differences Multidimensional Scaling) on SPSS. Such an additional procedure allowed for the verification of the structural dimensions of data, particularly useful when conducting cross-cultural analyses (Leung \& Bond, 1989). This technique is particularly valuable for the individual level of analysis, allowing for an examination of both the common 'cognitive space' shared by individuals, based on interstimulus proximities and distances, and the 'personal/private' space - a structure of individual differences plotted against the background of shared reference points (Tacq, 1997). This is especially useful when examining the distances between pairs of theoretically relevant stimuli across respondent groups.

Figure 2 shows the derived stimulus configuration for all participants. Parsimonity in number of dimensions selected is central to the interpretability of solutions (Purkhardt \& Stockdale, 1993). A two-dimensional solution, one on the horizontal axis (dimension 1) and the other on the vertical axis (dimension 2) was seen as optimal for this solution, and levels of stress were acceptable given the numbers of items employed (Wierczorkowska, personal communication, December 1999). Dimension 1 had a mean importance for all subjects of 0.42 , and it was 0.31 for dimension 2. Because of the clear overlap between items in the factors and dimensions in the multivariate analyses, we maintained the labels from our factor analysis, labelling dimension 1 'Sex' and dimension 2 'Deadly Disease'. For dimension 1, Homosexuality (loading -1.16$)$, Condoms $(-1.14)$, Sex $(-0.92)$, Casual sex $(-0.91)$ and Prostitute ( -0.88$)$ could be contrasted with Africa (1.79), Death (1.17) and Fear (0.87). For dimension 2, Illicit drugs (1.57), Blood (1.38) and Homosexuality (0.96) could be contrasted with Africa $(-1.43)$ and Condoms $(-1.09)$. A 5 (culture) $\times 3$ (occupational group) $\times 2$ (gender) MANOVA on the two dimension scores examined cultural, occupational and gender variations in the two dimension scores. On both dimensions there were significant cultural

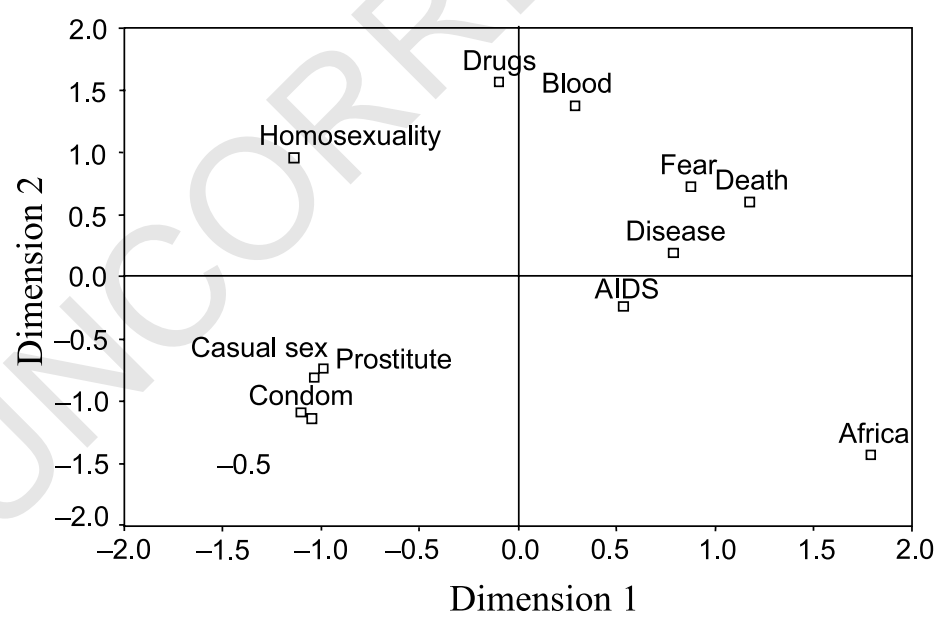

FIG. 2. Shared matrix from the multi-dimensional scaling analysis. 
variations $(F \mathrm{~s}(4,466)=9.69$ and $2.43, p<0.001$ and $<0.05$, for dimensions 1 and 2 , respectively) and gender differences $\left(F_{\mathrm{S}}(1,466)=8.40\right.$ and $8.82, p<0.01$, for dimensions 1 and 2, respectively). There were no significant occupational or second- or third-order effects. At the cultural level, the highest country score on dimension 1 ('Sex') was for Poland (0.69), followed by Hungary (0.67), Estonia (0.65), Georgia (0.63) and Russia (0.57). Post-hoc analyses revealed Poland to be significantly higher on dimension 1 than Estonia, Russia or Georgia. Highest on dimension 2 ('Deadly disease') was Estonia (0.57), followed by Georgia (0.55), Russia (0.54), Hungary (0.54) and Poland (0.52). Post-hoc analyses found Estonia to be significantly higher on this dimension than Russia, Hungary and Poland. Female respondents scored significantly higher on dimension 1 (the 'Sex' dimension: 0.62 versus 0.65 ) and lower on dimension 2 ('Deadly diseases': 0.54 versus 0.57 ) than their male counterparts $\left(F_{\mathrm{S}}(1,466)=8.38\right.$ and $8.98, p<0.001$, respectively).

To explore specific representations of out-groups, the relationship between pairs of particular associations between stimuli in each country was examined, selecting comparisons on the basis of previous research on out-group stigmatization of those with (or suspected of) HIV infection (Breakwell, 1993; Joffe, 1996; Sontag, 1989). Six comparisons were conducted: (1) AIDS and Drugs, (2) AIDS and Homosexuality, (3) AIDS and Casual sex, (4) AIDS and Africa, (5) Homosexuality and Casual sex, and (6) Condoms and Casual sex. This analysis was conducted adapting an application of Pythagorean theory where the squared distance $c$ is the product of the squared distances between the stimulus word AIDS and each member of the associations being contrasted (Davison, 1992). The proximity between the stimuli words AIDS and Homosexuality, AIDS and Casual sex and Homosexuality and Casual sex was greatest in Georgia ( $M$ distances of $1.71,1.43$ and 1.31 respectively, versus complete sample Ms of 2.05, 1.60 and 1.70). The association between AIDS and Drugs, Condoms and Casual sex and AIDS and Africa was closest in Russia (respective Ms of 0.65, 0.05 and 1.38, versus complete sample Ms of 2.00, 0.38 and 1.73).

\section{Discussion}

Despite growing concerns about the HIV/AIDS epidemic in Central and Eastern Europe, little research has been conducted into lay representations of the epidemic in this region. The analysis conducted in this paper explored the social representations of HIV/AIDS amongst business people and health professionals in five cultures, analyzing matrix data using two different multivariate techniques. The findings suggest two major factors or dimensions that underlie representations of this epidemic in the countries under discussion, dimensions termed 'Sex' and 'Deadly disease'. Despite relatively high levels of congruency between the five countries on these factors, and between the occupational groups in our sample, notable cultural variations did emerge in scores on the first dimension ('Sex') and in the distances between pairs of stimuli following the multidimensional scaling analysis.

The increase of HIV infection in Eastern Europe can primarily be seen as arising from the sharing of needles and syringes by those using illicit drugs (Donoghoe, 2003; Hamers \& Downs, 2003). The professional groups in this study provided mixed evidence concerning the associations they make between illicit drugs and the epidemic. In the free association tasks only a third of respondents (160) mentioned illicit drug use when free-associating with AIDS, a similar number to those who associated homosexuality with AIDS (148). In the MDS analyses, however, it is clear that respondents were at least moderately aware of the association between AIDS, blood and drugs in this region, locating blood and drugs closer than sexual behaviour to disease and AIDS (Figure 2). Notably, this association was strongest in the 'Eastern' European countries of Russia, Georgia and Estonia, where indeed the 
relationship between the epidemic spread and injecting drug use is strongest - and weakest in Hungary, where infection through intravenous drug use is comparatively rare (UNAIDS, 2002b).

The multidimensional analyses produced two major factors/dimensions. One dimension groups together casual sexual activity, condoms, prostitution and sexual activity in general and reflects the sexual component of the epidemic. A second dimension emphasizes the disease aspect of the epidemic and the fear associated with this. In the analysis of associations between specific stimulus words, Georgian respondents associated AIDS most closely with homosexuality and casual sexual activity. Páez et al. (1991) have suggested a relatively 'conservative' and 'moralizing' representation that sees HIV/AIDS as a disease amongst pariah, fringe social groups, with such a conservative representation strongest amongst the most religious. Notably, over $90 \%$ of the samples in Poland and Georgia identified themselves as belonging to a specific religion. In parallel studies conducted in these five nations, Poland and Georgia also scored highest on conservative values (conformity, tradition and security) (Goodwin et al., 2002). In a further series of semi-structured interviews, respondents from these two countries were most likely to see those at risk from contracting HIV/AIDS as belonging to an 'out-group' that included prostitutes, those engaging in casual sexual activity and those that carried condoms (Goodwin et al., 2003). Such conservative representations may have significant implications for safer sexual behaviour (Paez et al., 1991). Older Georgians in particular have been described as holding 'Victorian England' attitudes towards sexuality and have shown a notable reluctance to use condoms (UNAIDS, 2002a). The findings reported here therefore emphasize the need for a community-focused approach that helps address prevailing representations in the light of existing conservative perspectives and religious sensibilities (Danziger, 1994; Delor \& Hubert, 2000).

Russian respondents were the least likely to place together words on the second dimension, 'Sex'. This may reflect a relative reluctance to moralize in a society where there has been considerable confusion about sexual relations following the end of Communism in this country, and where the marked eroticization of culture has been accompanied by considerable ambiguity about the rights and wrongs of sexual behaviour (Kon, 1995). At the same time, these Russian respondents demonstrated the greatest proximity between 'Africa' and AIDS, with the analysis of the Russian data showing the strongest loading for Africa on the second dimension, 'Deadly disease'. Such a finding suggests a potential psychological 'distancing' in this country that may allow a sense of detachment from those perceived to be 'at risk'. Such a detachment can have important implications for risk behaviours by encouraging a sense of personal invulnerability and may contribute to a pattern of high-risk behaviour, including illicit injecting drug use and risky sexual practices (Lear, 1995).

Gender differences in these findings might also be partly interpreted in line with cultural variations in values, as well as prevailing concerns about the risk of infection. Women were more likely to group together items that formed the 'conservative' first dimension ('Sex') echoing gender differences in conservative values (Goodwin et al., 2002) - as well as previous research reporting a closer association between sexual activity and condom use amongst women (Bajos \& Marquet, 2000). Gender differences in mean scores on the 'Sex' dimension were highest in Poland, whilst differences in reported sexual activity were greatest in Georgia. These findings are consistent with Bajos and Marquet's (2000) observation that differences in sexual behaviour are likely to be greatest in more traditional cultures. Men were more likely than women to cluster items that emphasize the disease and death aspect of the epidemic. This parallels similar findings in other work in these countries: in this research men were more than four times as likely as women to report that they had had sex with a high-risk partner, more than twice as likely to claim that they used condoms primarily to avoid sexual disease, 
and were significantly more likely to worry about being at risk of contracting the disease (Goodwin et al., 2003).

Of course, an analysis of associations between stimulus items is only one possible route into understanding the complex ecological and social factors that underpin sexual behaviour (Barnett et al., 2000; Hobfoll, 1998; McAuliffe, 1996), and the exploratory study reported in this paper raises as many questions as it answers. The major route of transmission in this region is through illicit drug injection using infected needles (Hamers \& Downs, 2003) and we are currently exploring the representations of high-risk street children with particular reference to such drug use. Future research should also strive to incorporate a greater range of geographical locations, both urban and rural, and should include other countries at risk from the spread of the epidemic, particularly additional countries from the Former Soviet Union, the main area of infection in this region. Finally, future research needs to include a wider variety of indices and methods, locating emerging findings within the pressing ecological demands currently faced by the residents of this region.

The number of HIV/AIDS cases in Central and Eastern Europe is still not large compared, for example, to Sub-Saharan Africa. As a consequence, it should still be possible to limit the size of the epidemic in this region (Kalichman et al., 2000). However, as Markova (1992) notes, health campaigns rarely integrate scientific and social representational knowledge and in the region under investigation in this study there are few active organized groups of people at risk of HIV/AIDS to help counteract misleading representations of the epidemic. Health professionals in these countries should recognize the role social representations play in future peer- and community-based social interventions, and should actively challenge misleading representations in their efforts to address the rapidly growing epidemic in this region.

\section{Acknowledgements}

This paper was supported by a group grant to the authors from the Soros Foundation and led by the first author (1998/56). We would like to thank Ahto Külvet and Andu Rämmer for their help in collecting data and Grazyna Wieczorkowska-Nejtardt and Shalom Schwartz for their statistical advice on an earlier version of this paper.

\section{Notes}

[1] HIV/AIDS cases and estimated infection have increased very rapidly in Estonia since the time of this study, with the increase between 2000 and 2001 described by UNAIDS (2002b) as 'extremely alarming'. During 2001, 1,470 new HIV-positive cases were reported, with $89 \%$ of these aged under 30, and an estimated 7,700 people were living with HIV/AIDS in Estonia at the end of 2001. AIDS cases have also increased relatively sharply in Georgia since the time of this data collection, with a total of 310 cases registered by the Infectious Diseases, AIDS and Clinical Immunology Research Centre in Tbilisi by June 2002 (UNAIDS, 2002a). In both countries, infection increase can be largely traced to the injection of illegal drugs and needle and syringe sharing.

\section{References}

Abrahams, C., Sheeran, P. \& Orbell, S. (1998). Can social cognitive models contribute to the effectiveness of HIVpreventive behavioural interventions? British fournal of Medical Psychology, 71, 297-310.

Albarracín, D., Johnson, B.T., Fishbein, M. \& Muellerleile, P.A. (2001). Theories of reasoned action and planned behavior as models of condom use: a meta-analysis. Psychological Bulletin, 127, 142-161.

Amirkhanian, Y.A., Kelly, J.A. \& Issayev, D.D. (2001). AIDS knowledge, attitudes, and behavior in Russia: results of a population-based, random-digit telephone survey in St. Petersburg. International fournal of STDs and AIDS, $12,50-57$. 
Atlanti, L., Carael, M., Brunet, J.B., Frasca, T. \& Chaika, N. (2000). Social change and HiV in the former USSR: the making of a new epidemic. Social Science and Medicine, 50, 1547-1556.

Bajos, N. \& Marquet, J. (2000). Research on HIV sexual risk: a social relations-based approach in a cross-cultural perspective. Social Science and Medicine, 50, 1533-1546.

Barnett, T., Whiteside, A., Khodakevich, L., Kruglov, Y. \& Steshenko, V. (2000). The HiV/AIDS epidemic in Ukraine: its potential social and economic impact. Social Science and Medicine, 51, 1387-1403.

BERGMANN, M.M. (1999). Would the real social representation please stand up? Three levels of analysis of European American and Mexican American identity. Papers on Social Representations, 8, 4.1-4.7.

Borisenko, K.K., Tichonova, L.I. \& Renton, A.M. (1999). Syphilis and other sexually transmitted infections in the Russian Federation. International fournal of STDs and AIDS, 10, 665-668.

BREAKwell, G.M. (1993). Integrating paradigms: methodological implications. In: Breakwell, G. M. \& CANTER, D. V. (Eds), Empirical approaches to social representations (pp. 180-201). Oxford: Clarendon Press.

Breakwell, G.M. \& CANTER, D.V. (1993). Empirical approaches to social representations. Oxford: Clarendon Press.

CAMPBELl, C. (2001). More questions than answers? The impact of the HIVIAIDS epidemic on our understanding of social and community structures. Paper presented at the Biosocial Society Symposium 'Learning from HIVIAIDS: Transdisciplinary perspective. London: Institute of Education.

DANZIGer, R. (1994). Discrimination against people with HIV and AIDS in Poland. British Medical fournal, 308, 1145-1147.

DAvison, M.L. (1992). Multidimensional scaling. Malabor, Fla: Krieger.

Dehne, K.L., Pokrovsky, V., Kobychscha, Y. \& Schwartländer, B. (2000). Update on the epidemics of HIV and other sexually transmitted infections in the newly independent states of the former Soviet Union. AIDS, 14, s75s84.

Delor, F. \& Hubert, M. (2000). Revisiting the concept of 'vulnerability'. Social Science and Medicine, 50, 15571570.

Di Giacomo, J.P. (1980). Intergroup alliances and rejections within a protest movement. European fournal of Social Psychology, 10, 329-344.

Doise, W., Clemence, A. \& Lorenzi-Cioldi, F. (1993). The quantitative analysis of social representations. London: Harvester Wheatsheaf.

Donoghoe, M.C. (2003). HIV-1 in Eastern Europe. Lancet, 361, 1910-1911.

Echebarria, A.E. \& PÁez, D. (1989). Social representations and memory: the case of AIDS. European fournal of Social Psychology, 19, 543-551.

Estonian Drug Monitoring Centre (2003). National report on the drug situation in Estonia. Tallinn: Institute of Experimental and Clinicial Medicine, Estonian Drug Monitoring Centre.

FARR, R. (1984). Les représentations sociales. In: MoscovicI, S. (Ed.), Psychologie sociale. Paris: Presses Universitaires de France.

Fife-Schaw, C. (1997). Commentary on Joffe (1996), 'AIDS research and prevention: a social representation approach'. British fournal of Medical Psychology, 70, 65-73.

AQ2 Goodwin, R., Kozlova, A., Kwiatkowska, A., Nguyen luu, L.A., Nizharadze, G., Realo, A., Kulvet, A. \& Rammer, A. (2003). Social representations of HIV/AIDS in Central and Eastern Europe. Social Science and Medicine.

Goodwin, R., Realo, A., Kwiatkowska, A., Kozlova, A., Nguyen Luu, L.A. \& Nizharadze, G. (2002). Values and sexual behavior in Central and Eastern Europe. Fournal of Health Psychology, 7, 45-56.

Hamers, F.F. \& Downs, A.M. (2003). HIV in Central and Eastern Europe. Lancet, 361, 1035-1044.

HeAdley, D. (1998). HIVIAIDS in Russia. London: Charities Aid Foundation, Russian Office.

Hobfoll, S.E. (1998). Ecology, community, and AIDS prevention. American fournal of Community Psychology, 26, 133-144.

Hobfoll, S.E., Jackson, A.P., LAvin, J., Britton, P.J. \& Shepherd, J.B. (1993). Safer sex knowledge, behavior, and attitudes of inner-city women. Health Psychology, 12, 482-488.

AQ4 Jodelet, D. (1989). Représentations Sociales: un domaine en expansion. In: Jodelet, D. (Ed.), Les Représentations Sociales. Paris: Presses Universitaires de France.

JofFe, H. (1996). AIDS research and prevention: a social representation approach. British fournal of Medical Psychology, 69, 169-190.

Kalichman, S.C. (1998). Preventing AIDS: a sourcebook of behavioral interventions. Mahwah, NJ: Lawrence Erlbaum.

Kalichman, S.C., Kelly, J.A., Sikkema, K.J., Koslov, A.P., Shaboltas, A. \& Granskaya, J. (2000). The emerging AIDS crisis in Russia: review of enabling factors and prevention needs. International fournal of STDs and AIDS, 11, 71-75. 
Kallasmaa, T., Allik, J., Realo, A. \& McCrae, R.R. (2000). The Estonian version of the NEO-PI-R: an examination of universal and culture-specific aspects of the Five-Factor Model. European fournal of Personality, 14, 265-278.

Kitzinger, J. (1995). The face of Aids. In: MARkova, I. \& FARR, R. (Eds), Representations of health, illness and handicap (pp. 49-66). London: Harwood Press.

Kon, I. (1995). The sexual revolution in Russia: from the age of the czars to today. New York: Free Press.

LEAR, D. (1995). Sexual communication in the age of AIDS: the construction of risk and trust among young adults. Social Science and Medicine, 41, 1311-1323.

LEUNG, K. \& Bond, M. (1989). On the empirical identification of dimensions for cross-cultural comparison. Fournal of Cross-Cultural Psychology, 20, 133-151.

Markova, I. (1992). Scientific and public knowledge of AIDS: the problem of their integration. In: VON CRANACH, M., Doise, W. \& Mugny, G. (Eds), Social representations and the social bases of knowledge. Lewiston: Hogrefe \& Huber.

Markova, I. \& WiLkie, P. (1987). Representations, concepts and social change: the phenomenon of AIDS. Fournal for the Theory of Social Behaviour, 17, 389-409.

MANnetTI, L. \& TANUCCI, G. (1993). The meaning of work for young people: the role of parents in the transmission of a social representation. In: BREAKwell, G. \& CANTER, D. (Eds), Empirical approaches to social representations (pp. 298-314). Oxford: Clarendon Press.

McAuliffe, E. (1996). AIDS: barriers to behavior change in Malawi. In: Grad, H., Blanco, A. \& Georgas, J (Eds), Key issues in cross-cultural psychology. Lisse: Swets \& Zeitlinger.

Morin, M., Souville, M. \& Obadia, Y. (1996). General practitioners' attitudes, mental representations, and practices with regard to patients infected with HIV [in French]. Cahiers Internationaux de Psychologie Sociale, 29, $9-$ 28.

Moscovici, S. (1984). The phenomenon of social representations. In: FARr, R.M. \& Moscovici, S. (Eds), Social representations. Cambridge: Cambridge University Press.

Moscovici, S. \& Perez, J.A. (1997). Representations of society and prejudices. Papers on Social Representations, 6, $27-36$.

Nascimento-Schulze, C.M., Fontes Garcia, Y. \& Arruda, D.C. (1995). Health paradigms, social representations of health and illness and their central nucleus. Papers on Social Representations, 4, 187-198.

Páez, D., Echebarria, A., Valencia, J., Romo, I., San Juan, C. \& Vergara, A. (1991). AidS social representations: contents and processes. Fournal of Community and Applied Social Psychology, 1, 89-104.

Parker, R.G., EAston, D. \& KLeIN, C.H. (2000). Structural barriers and facilitators in HIV prevention: a review of international research. AIDS, 14 (Suppl. 1), S22-S32.

Purkhardt, S.C. \& Stockdale, J.E. (1993). Multidimensional scaling as a technique for the exploration and description of a social representation. In: BREAKwell, G. \& CANTER, D. (Eds), Empirical approaches to social representations (pp. 272-297). Oxford: Clarendon Press.

Rhodes, T., Stimson, G.V., Crofts, N., Ball, A., Dehne, K. \& Khodakevich, L. (1999). Drug injecting, rapid HIV spread, and the 'risk environment': implications for assessment and response. AIDS, 13 (Suppl. A), S259S269.

RIVkin-Fish, M. (1999). Sexuality education in Russia: defining pleasure and danger for a fledgling democratic society. Social Sciences and Medicine, 49, 801-814.

Roccas, S. \& Schwartz, S.H. (1997). Church-state relations and the association of religiosity with values: a study of Catholics in six countries. Cross-Cultural Research, 31, 356-375.

Rosenbrock, R., Dubois-Arber, F., Moore, M., Pinell, P., Schaeffer, D. \& Setbon, M. (2000). The normalization of AIDS in Western European countries. Social Science and Medicine, 50, 1607-1629.

Sheeran, P., Abraham., C. \& Orbell, S. (1999). Psychosocial correlates of heterosexual condom use: a metaanalysis. Psychological Bulletin, 125, 90-132.

SonTAg, S. (1989). AIDS and its metaphors. New York: Doubleday.

TACQ, J. (1997). Multivariate analysis techniques in social science research. New York: Sage.

UNAIDS (2002a). Response analysis on HIV/AIDS in Georgia. Tblisi, June.

UNAIDS (2002b). Global HIVIAIDS and STD Surveillance: Epidemiological Factsheets. December. Available at: http:// www.unaids.org

WAGNER, W. (1995). Description, explanation and method in social representation research. Papers on Social Representations, 4, 156-176. Reiss' hypotheses about Sweden and the United States. Fournal of Sex Research, 37, 44-52. 


\section{AUTHOR'S QUERY SHEET}

Author(s): R. GOODWIN ET AL. caic 160602

Article title:

Article no:

Dear Author

Some questions have arisen during the preparation of your manuscript for typesetting. Please consider each of the following points below and make any corrections required in the proofs.

Please do not give answers to the questions on this sheet. All corrections should be made directly in the printed proofs.

AQ1 Farr, 1984 - translation needed.

AQ2 Goodwin et al., 2003 - rest of details, i.e. volume, number, pp.?

AQ3 Hobfoll et al., 1993, Please provide citation in text.

AQ4 Jodelet, 1989 - translation needed also please provide citation in text.

AQ5 Markova, 1992 - where is Lewiston? Which country or US state is it in?

AQ6 Roccas \& Schwartz, 1997 - please provide citation in text.

AQ7 Weinberg et al., 2000 - Please provide citation in text. 